\title{
Development and Control of a Prototype Pneumatic Active Suspension System
}

\author{
Winfred K.N. Anakwa, Dion Thomas, Scott Jones, Jon Bush, Dale Green, \\ George Anglin, Ron Rio, Jixiang Sheng, Scott Garrett and Li Chen. \\ Department of Electrical \& Computer Engineering \\ Bradley University \\ Peoria, IL 61625
}

\begin{abstract}
Real physical plants for control experimentation are valuable tools in a control laboratory. This paper describes a prototype pneumatic active suspension system, which was designed and built over a number of years as a sequence of student projects. The physical plant, which models a quarter-car suspension, consists of a wheel, coil springs, a pneumatic actuator for active damping, position and velocity sensors, and an AC motor for simulating road disturbance input signal. An electronic subsystem is used to process the sensor signals which are sent to a Motorola $68 \mathrm{HC} 16$ microcontroller-based evaluation board. The microcontroller controls a 4-bit automatic binary regulator which controls airflow to the pneumatic actuator for damping. A mathematical model of the suspension system was derived analytically and validated experimentally. Matlab and Simulink were used to analyze and design a digital state feedback plus integral controller for the system. The digital controller was implemented on a Motorola $68 \mathrm{HC} 16$ microcontroller. The controller was able to reject a physically generated $0.01143 \mathrm{~m}$ negative step road disturbance input. The details of the design construction, modeling, analysis, computer simulation, controller implementation and experimental results are presented.
\end{abstract}

\section{Introduction}

In order for students to gain experience in design and construction of a physical plant, as well as control experimentation, a decision was made in the fall of 1990 to build a prototype pneumatic active suspension system as a student project. The suspension system was selected at that time because the automotive industry was seriously considering implementation of active suspension systems on automobiles $^{1-8}$. A quarter-car model was selected because it would be feasible to test in a laboratory environment. Pneumatic actuation was chosen instead of hydraulic actuation to avoid the possibility of oil spill in the laboratory. The design, construction and the physical structure are presented in section II, and the associated sensors and actuator electronics are covered in section III. The mathematical modeling, computer simulation and experimental validation of the 
model are presented in section IV. The design of the digital control algorithm, its implementation on a Motorola $68 \mathrm{HC} 16$ microcontroller-based evaluation board and experimental results are given in section V. Final conclusions are summarized in section VI.

\section{Design and Physical Structure}

A typical quarter-car model of an active suspension can be modeled as a system consisting of masses, springs, a passive damper, and an active damper as shown in Figure 1 below.

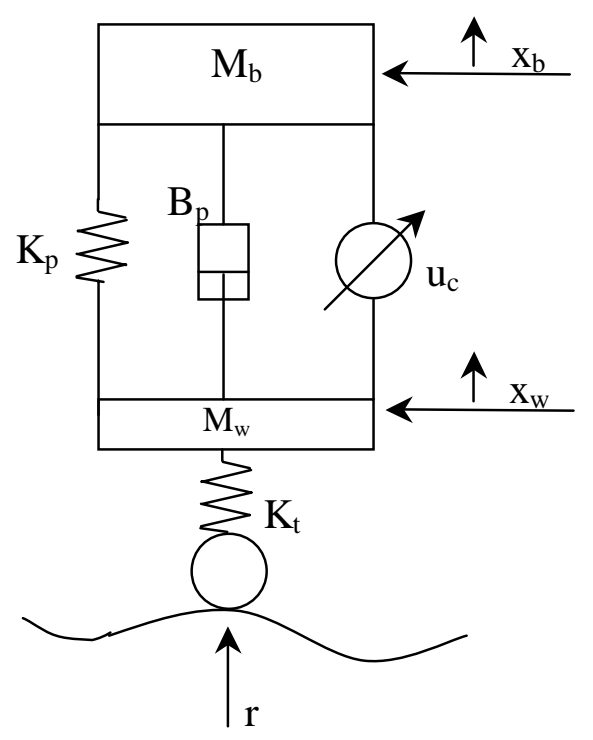

Figure 1 Diagram of Suspension System

The parameters in Figure 1 are:

$\mathrm{M}_{\mathrm{b}}=$ mass of driver and seat.

$\mathrm{M}_{\mathrm{w}}=$ mass of wheel and tire.

$\mathrm{K}_{\mathrm{p}}=$ spring constant of coil of shock absorber.

$\mathrm{B}_{\mathrm{p}}=$ damping coefficient of hydraulic damper.

$\mathrm{K}_{\mathrm{t}}=$ spring constant of tire.

$\mathrm{u}_{\mathrm{c}}=$ active control input force.

$\mathrm{r}=$ road disturbance input.

$\mathrm{x}_{\mathrm{b}}=$ displacement of $\mathrm{M}_{\mathrm{b}}$.

$\mathrm{x}_{\mathrm{w}}=$ displacement of $\mathrm{M}_{\mathrm{w}}$.

Some standard values taken from ${ }^{9-10}$ are:

$$
\begin{aligned}
& \mathrm{M}_{\mathrm{b}}=290 \mathrm{~kg} \\
& \mathrm{M}_{\mathrm{w}}=59 \mathrm{~kg} \\
& \mathrm{~K}_{\mathrm{p}}=16812 \mathrm{~N} / \mathrm{m} \\
& \mathrm{B}_{\mathrm{p}}=1000 \mathrm{~N} /(\mathrm{m} / \mathrm{sec}) \\
& \mathrm{K}_{\mathrm{t}}=190000 \mathrm{~N} / \mathrm{m}
\end{aligned}
$$

The objective was to design and construct a laboratory scale quarter-car pneumatic active suspension system with the following specifications.

$$
\mathrm{M}_{\mathrm{b}}=22.34 \mathrm{~kg}
$$




$$
\begin{aligned}
& \mathrm{M}_{\mathrm{w}}=4 \mathrm{~kg} \\
& \mathrm{~K}_{\mathrm{p}}=11624.85 \mathrm{~N} / \mathrm{m} \\
& \mathrm{B}_{\mathrm{p}}=500 \mathrm{~N} /(\mathrm{m} / \mathrm{s}) \\
& \mathrm{K}_{\mathrm{t}}=11207.56 \mathrm{~N} / \mathrm{m}
\end{aligned}
$$

The physical system was an assembly of a sprung mass, two linear springs, pneumatic cylinder and valving, along with position and velocity sensors. A three-phase inverter-controlled A.C. gearmotor driving a cam was included for generation of a sinusoidal road surface disturbance input. The signals from the sensors were processed by a microcomputer which controlled the pneumatic damper.

The engineering analysis and calculations leading to the selection of system components is now discussed. The mechanism for road disturbance input was developed with the goal of driving the suspension system in the vertical direction. It was found that a circular cam with an offset bore would produce a very good approximation of a sinusoidal waveform when driving a load placed upon its surface. The cam had $0.0254 \mathrm{~m}$ stroke and it generated a waveform modeled as:

$$
\mathrm{r}(\mathrm{t})=0.0127 \sin \omega \mathrm{t}
$$

where $\omega$ was a function of the speed of rotation of the cam. Next, a motor was selected to drive the cam. The motor rating was determined using the following assumptions:

Maximum value of $\omega=28.27 \mathrm{rad} / \mathrm{sec}$.

Maximum load mass $\mathrm{m}=75 \mathrm{~kg}$.

Generated waveform $\mathrm{r}(\mathrm{t})=0.0127 \sin \omega \mathrm{t}$.

Maximum velocity $\mathrm{v}=\frac{d r(t)}{d t}=0.359 \mathrm{~m} / \mathrm{sec}$.

Maximum acceleration $\mathrm{a}=\frac{d^{2} r(t)}{d t^{2}}=10.15 \mathrm{~m} / \mathrm{sec}^{2}$.

Maximum force $\mathrm{F}=\mathrm{ma}=761.4 \mathrm{~N}$.

Power equation Power $=\mathrm{Fv}=273.3 \mathrm{~W}$.

Horse Power $\mathrm{Hp}=\frac{273.3}{746}=0.37 \mathrm{Hp}$.

A $0.5 \mathrm{Hp}$ Dayton three phase A.C. gear motor with rated full load torque of $11.30 \mathrm{~N}-\mathrm{m}$ and no load speed of $288 \mathrm{rpm}$ was selected.

In order to provide capability for varying the frequency of the road disturbance input signal, a motor speed controller was needed. The Toshiba ESP-130 transistor inverter VF 10S-20 15BO, equipped with a frequency meter, an adjustable dial and a run-stop switch was chosen for motor speed control. Figure 2 shows the wiring diagram of the inverter connected to the A.C. motor.

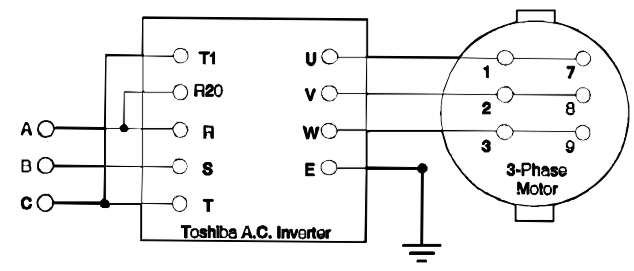

Figure 2. Gearmotor and Inverter Wiring Schematic 
The inverter made it possible to attain a low frequency road disturbance input signal $r(t)=0.0127 \sin 5.7 \mathrm{t}$ meters. The analysis leading to the selection of an air cylinder for active damping is discussed next. The sizing of the air cylinder was determined assuming that the total load consisted of any frictional loads in the system, the force exerted by maximum sprung mass, the force needed to accelerate the sprung mass, and the force required to exhaust the air from the other end of the cylinder. The loads were:

Force due to sprung mass $=22.4 \mathrm{~kg} \times 9.8 \mathrm{~m} / \mathrm{sec}^{2} \cong 220 \mathrm{~N}$.

Acceleration force $\cong 22.4 \mathrm{~kg} \times 12.5 \mathrm{~m} / \mathrm{sec}^{2} \cong 280 \mathrm{~N}$.

Frictional and exhaust forces $\cong 222.5 \mathrm{~N}$.

Total load $\cong 722.5 \mathrm{~N}$.

After calculating the total load, a working pressure of $2.76 \times 10^{5} \mathrm{~Pa}$ was chosen to size the cylinder. Using the equations:

Force $=$ Pressure $\mathrm{x}$ Area

$722.5 \mathrm{~N}=2.76 \times 10^{5} \times \mathrm{A}$

a minimum piston area of $0.00262 \mathrm{~m}^{2}$ was obtained. This yielded a minimum cylinder bore diameter of approximately $0.058 \mathrm{~m}$. Appropriate cushions were selected for the air cylinder to avoid damage due to shock. Since the cam produced a total stroke of $0.0254 \mathrm{~m}$, Parker Fluid power air cylinder model 2.50CTCMA14C x 3.00 with $0.0762 \mathrm{~m}$ stroke was selected. For control of airflow to the air cylinder, Parker Fluidpower 4-bit automatic binary regulator ABR model W21540179P, and Parker Fluidpower three unit air line regulator, filter, lubricator were selected. Additional components selected before assembling the active suspension system were:

Two chrome vanadium springs with spring constant $5812.425 \mathrm{~N} / \mathrm{m}$.

Two stainless steel guide rods and bearing.

Two Bourns Linear potentiometer position sensors.

Two magnetic linear velocity sensors with $1.772 \mathrm{~V} / \mathrm{m} / \mathrm{sec}$.

One cam follower with spring constant $11207.56 \mathrm{~N} / \mathrm{m}$.

Parker Fluidpower air line hoses.

Parker Fluidpower air line couplings.

The cam was designed by a student and the design was sent to Kress Corporation for fabrication ${ }^{11}$. The physical structure of the active suspension system resulting from assembling the components is shown in Figure 3.

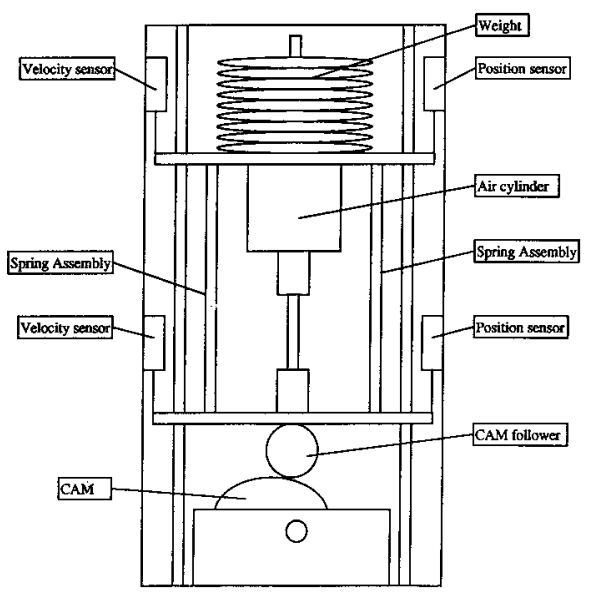

Figure 3. Physical Structure of Active Suspension System 
A photograph of the active suspension system is shown in Figure 4.

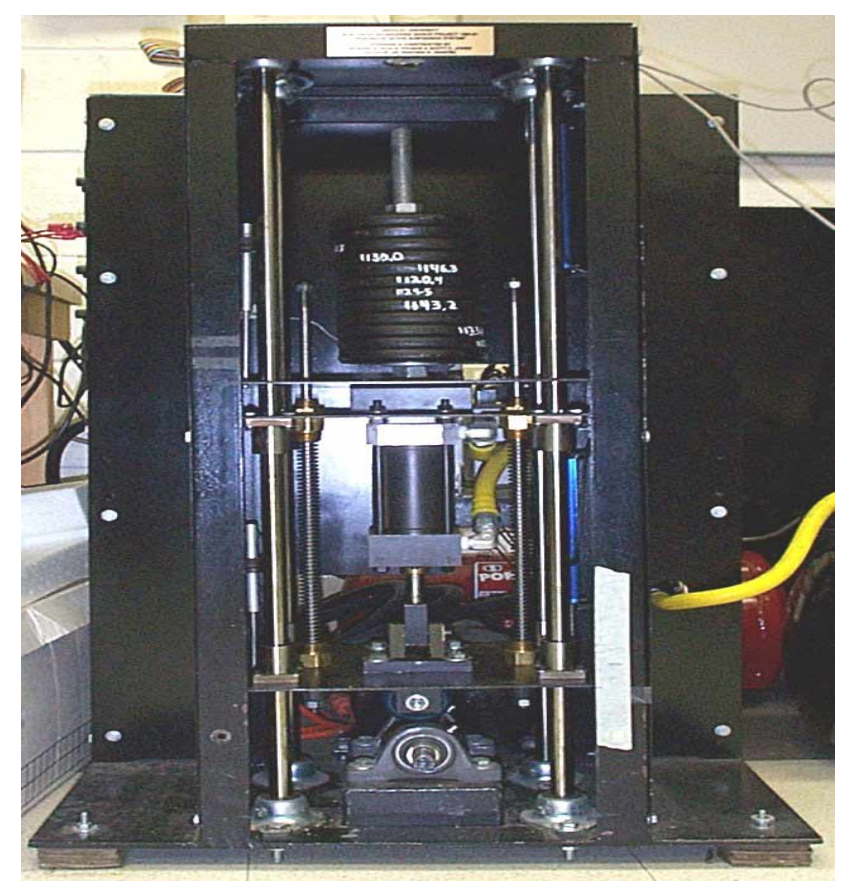

Figure 4. Photograph of Active Suspension System

An air compressor supplying air at $0.552 \mathrm{MPa}$ and two air storage tanks were used to maintain the air pressure at the inlet of the 4-bit regulator at approximately $0.276 \mathrm{MPa}$ during operation.

\section{Sensor and Actuator Electronics}

The sprung mass position and wheel mass position, shown in Figure 1, were measured by identical linear Bourns potentiometers. Two identical amplifier and filter combination circuits were used to process the measured position signals. Figure 5 shows the amplifier and filter circuit.

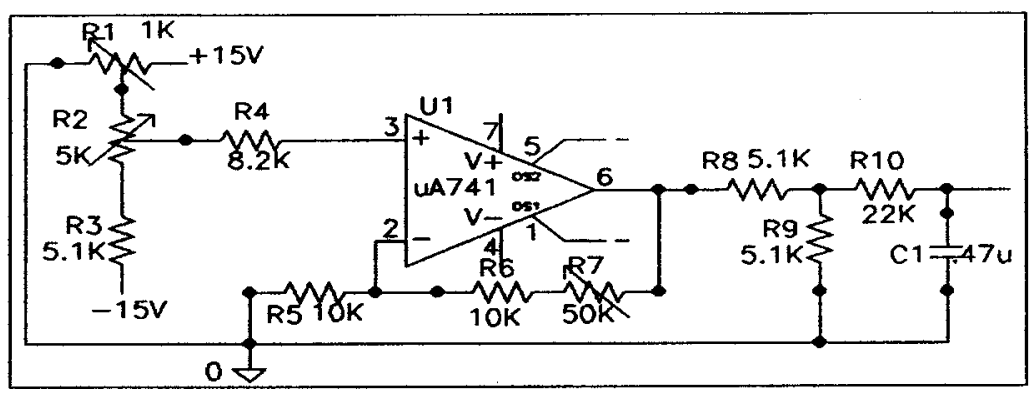

Figure 5. Position Sensor Amplifier and Filter Circuit 
The circuit in Figure 5 was calibrated to produce $81.10 \mathrm{~V} / \mathrm{m}$. The velocities of the sprung mass and wheel mass were measured by identical magnetic linear velocity sensors. Two identical amplifier and filter combination circuits were used to process the measured velocity signals. Figure 6 shows the amplifier and filter circuit.

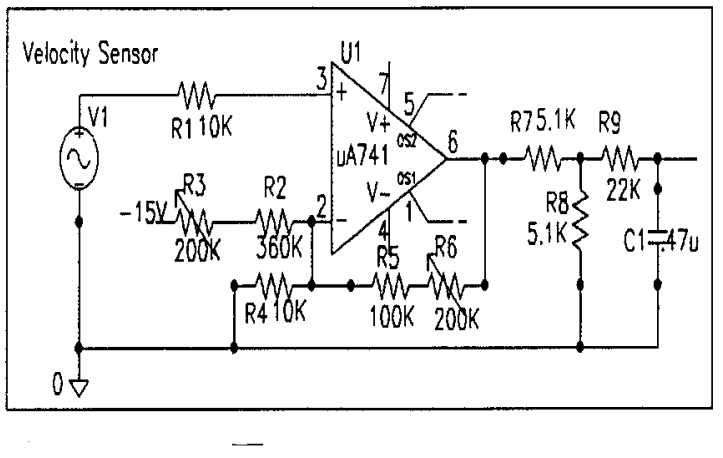

Figure 6. Velocity Sensor Amplifier and Filter Circuit

The circuit in Figure 6 was calibrated to produce $7.5 \mathrm{~V} / \mathrm{m} / \mathrm{sec}$.

In section $\mathrm{V}$, the microcontroller which used the position and velocity signals to control the pneumatic damper will be discussed. In the meantime, the circuit diagram of one of the four identical electronic circuits which control the 4-bit binary regulator valves is shown in Figure 7.

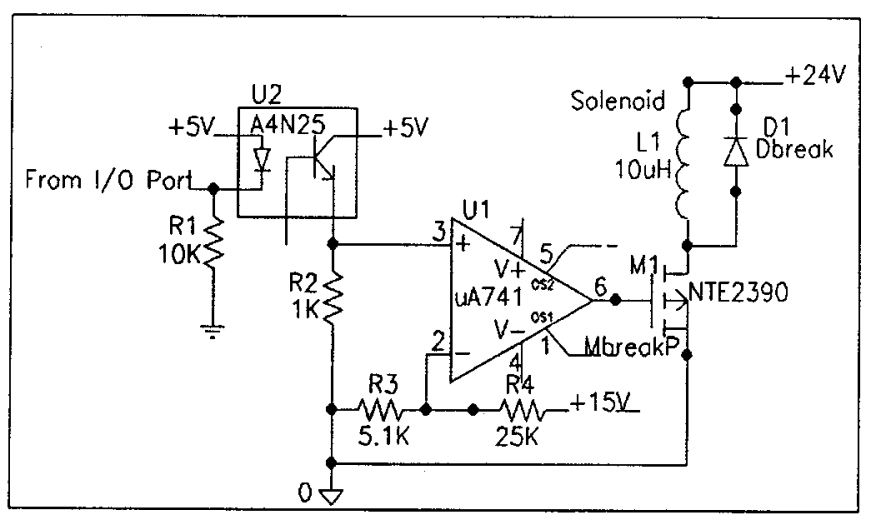

Figure 7. Control Circuit for Automatic Binary Regulator

The opto-isolator in Figure 7 was used to isolate the microcontroller from the high voltage circuit. The inductor in the circuit of Figure 7 represents one of the solenoids of the 4-bit binary regulator.

IV. Mathematical Modeling

Suppressing the argument $\mathrm{t}$, the equations of motion for the active suspension system of Figure 1 can be written as: 


$$
\begin{aligned}
& M_{b} \ddot{x}_{b}=-B_{p}\left(\dot{x}_{b}-\dot{x}_{w}\right)-K_{p}\left(x_{b}-x_{w}\right)+u_{c} \\
& M_{w} \ddot{x}_{w}=-B_{p}\left(\dot{x}_{w}-\dot{x}_{b}\right)-K_{p}\left(x_{w}-x_{b}\right)-K_{t}\left(x_{w}-r\right)-u_{c}
\end{aligned}
$$

When $\mathrm{u}_{\mathrm{c}}=0$, the transfer function from $\mathrm{r}$ to $\mathrm{x}_{\mathrm{b}}$ reduces to:

$$
\frac{X_{b}(s)}{R(s)}=\frac{B_{p} K_{t} s+K_{p} K_{t}}{\text { denom }}
$$

where denom $=\mathrm{M}_{\mathrm{b}} \mathrm{M}_{\mathrm{w}} \mathrm{s}^{4}+\mathrm{B}_{\mathrm{p}}\left(\mathrm{M}_{\mathrm{b}}+\mathrm{M}_{\mathrm{w}}\right) \mathrm{s}^{3}+\left(\mathrm{M}_{\mathrm{w}} \mathrm{K}_{\mathrm{p}}+\mathrm{M}_{\mathrm{b}} \mathrm{K}_{\mathrm{p}}+\mathrm{M}_{\mathrm{b}} \mathrm{K}_{\mathrm{t}}\right) \mathrm{s}^{2}+\mathrm{B}_{\mathrm{p}} \mathrm{K}_{\mathrm{t}} \mathrm{s}+\mathrm{K}_{\mathrm{p}} \mathrm{K}_{\mathrm{t}}$. When the active suspension system was excited with a sinusoidal input disturbance $r$, it was observed that the amplitudes of $r$ and $x_{w}$ were equal. This indicated that the tire was not compressed because $\mathrm{K}_{\mathrm{t}}$ was too large.

Consequently, the limiting form of (6) as $\mathrm{K}_{\mathrm{t}}$ approached infinity was calculated. As $\mathrm{K}_{\mathrm{t}}$ approached infinity (6) reduced to:

$$
\frac{X_{b}(s)}{R(s)}=\frac{B_{p} s+K_{p}}{s^{2} M_{b}+B_{p} s+K_{p}}
$$

Using numerical values of $\mathrm{M}_{\mathrm{b}}=22.34 \mathrm{Kg}, \mathrm{B}_{\mathrm{p}}=500 \mathrm{~N} / \mathrm{m} / \mathrm{s}$, and $\mathrm{K}_{\mathrm{p}}=11624.85 \mathrm{~N} / \mathrm{m}$ led to:

$$
\frac{X_{b}(s)}{R(s)}=\frac{500 s+11624.85}{22.34 s^{2}+500 s+11624.85}
$$

To validate the mathematical model given by (8), the response of the physical active suspension system to a negative disturbance step input $r$ of amplitude $0.01143 \mathrm{~m}$ was recorded. Equation (8) was simulated in Simulink with a scale factor of $81.10 \mathrm{~V} / \mathrm{m}$ to convert $\mathrm{x}_{\mathrm{b}}$ position signal to volts ${ }^{12}$. The physical system response and computer simulation response curves are shown in Figure 8.

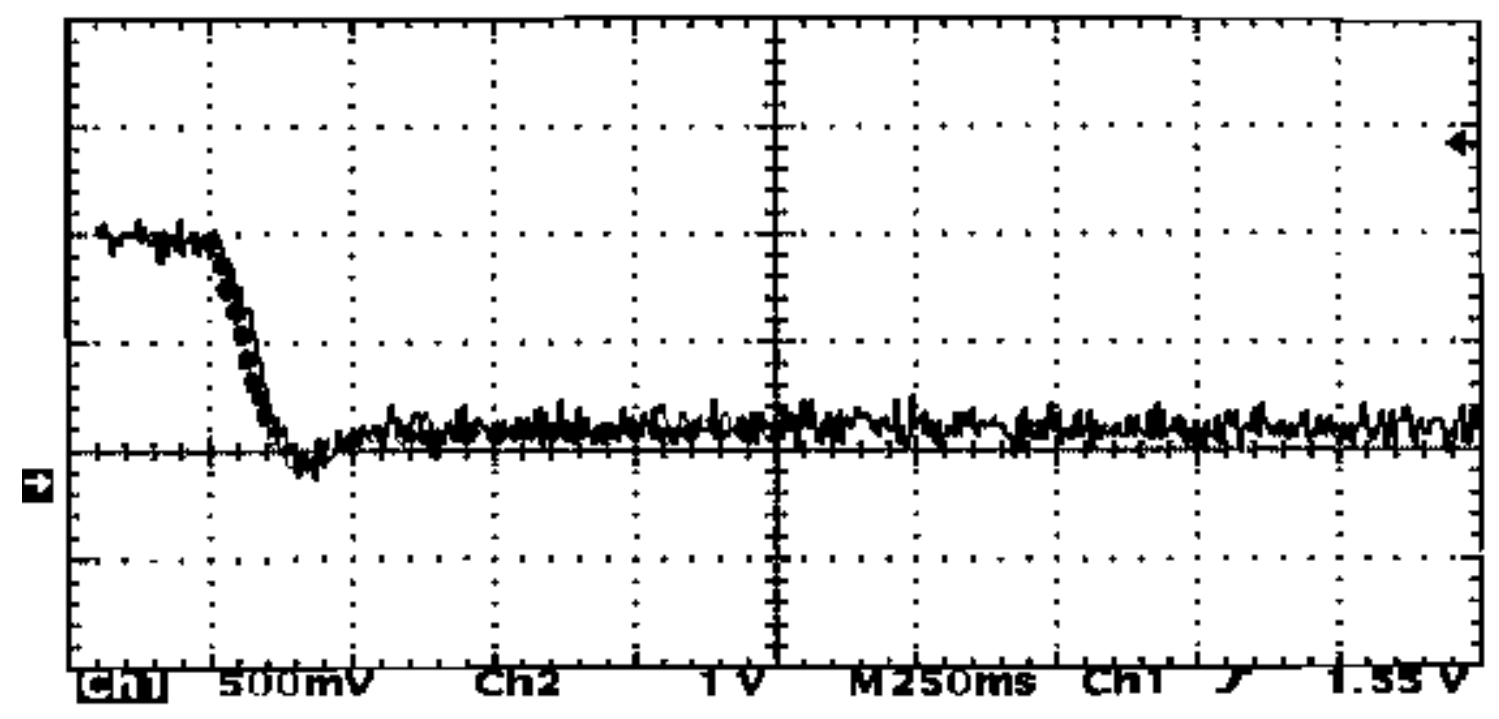

Figure 8. Experimental and Matlab Simulation Step Responses

In figure 8 , the continuous curve is the experimental step response, and the dotted curve is the computer simulation step response. The agreement between the two curves showed that equation (8) modeled the behavior of the suspension system without the actuator force $\mathrm{u}_{\mathrm{c}}$ fairly accurately. 
A separate experiment was performed to obtain a model for the combination of the 4-bit automatic binary regulator and the air cylinder which generated the control force $u_{c}$. In the experiment, the air pressure at the inlet of the automatic binary regulator was set at $0.2484 \mathrm{MPa}$. A computer program running on the Motorola $68 \mathrm{HC} 16$ opened the automatic binary regulator valve in increments of one bit from 0 to 15, while the corresponding waveforms of $\mathrm{x}_{\mathrm{b}}$ were recorded. From the experimental results, the transfer function from the binary regulator valve input bi to control force $\mathrm{u}_{\mathrm{c}}$ can be expressed as:

$$
\frac{u_{c}(s)}{b i(s)}=\frac{43.002}{0.055 s+1}
$$

The control force $\mathrm{u}_{\mathrm{c}}$ has units of Newtons.

Figure 9 shows a simulation diagram of the suspension system with road disturbance input $r$, binary regulator input bi and output $\mathrm{x}_{\mathrm{b}}$.

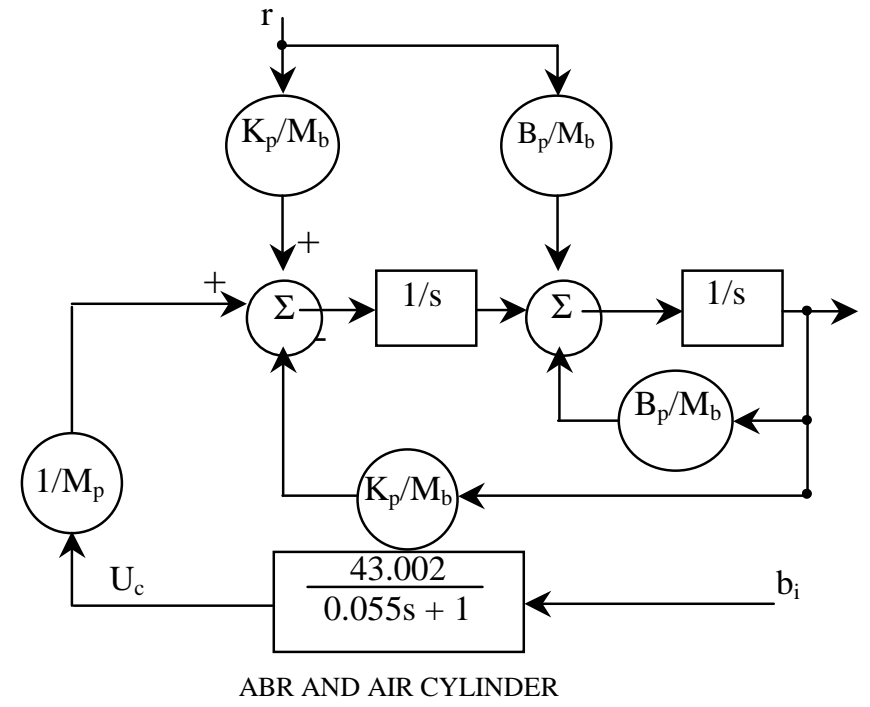

Figure 9. Simulation Diagram of Suspension System

Matlab simulation and experimental step responses of the suspension system from ABR input bi to $x_{b}$, when the disturbance input $r=0$, are shown in Figure 10 .

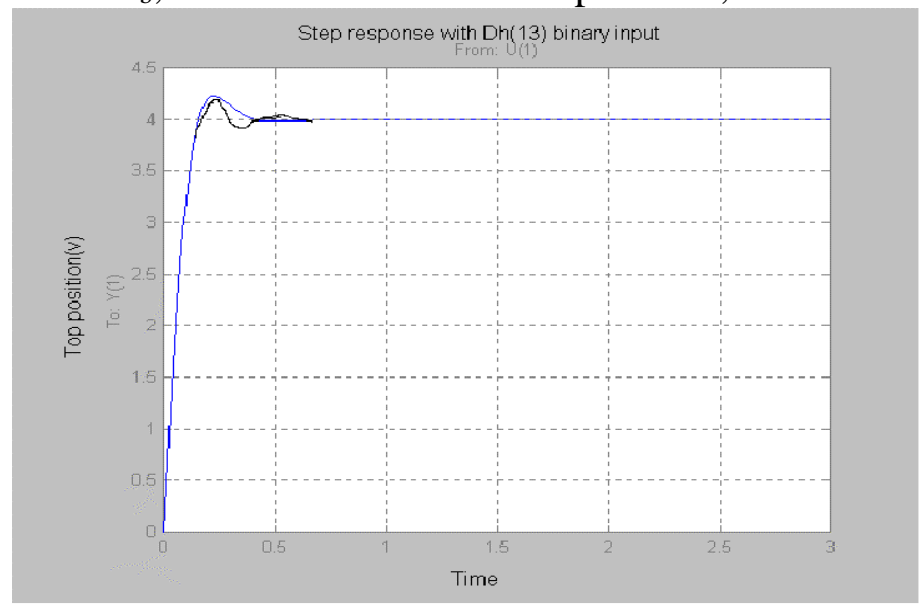

Figure 10. Matlab Simulation and Experimental Step Responses 
The upper curve is Matlab simulation and the lower curve is the experimental result. Since the experimental results agreed fairly well with computer simulation results, the mathematical model shown in the simulation diagram of Figure 9 was used to design a controller for the pneumatic suspension system.

V. Controller Design and Implementation

The state variable equation of the open loop system shown in Figure 9 was written as:

$$
\begin{aligned}
& \dot{x}=A x+B_{1} b_{i}+B_{2} r \\
& y=C x
\end{aligned}
$$

where,

$$
\begin{gathered}
\mathrm{A}=\left[\begin{array}{ccc}
\frac{-\mathrm{B}_{\mathrm{p}}}{\mathrm{M}_{\mathrm{b}}} & 0 & 0 \\
\frac{-\mathrm{K}_{\mathrm{p}}}{\mathrm{M}_{\mathrm{b}}} & 0 & \frac{1}{\mathrm{M}_{\mathrm{b}}} \\
0 & 0 & -18.182
\end{array}\right] \\
B_{1}=\left[\begin{array}{c}
0 \\
0 \\
781.8545
\end{array}\right] \\
B_{2}=\left[\begin{array}{c}
\frac{B_{p}}{M_{b}} \\
\frac{K_{p}}{M_{b}} \\
0
\end{array}\right], C=\left[\begin{array}{lll}
81.10 & 0
\end{array}\right]
\end{gathered}
$$

with variables:

$\mathrm{y}=\mathrm{x}_{\mathrm{b}}$ is the measured sprung mass displacement.

$\mathrm{r}=$ road disturbance input.

$\mathrm{b}_{\mathrm{i}}=$ input to the automatic binary regulator.

$\mathrm{M}_{\mathrm{b}}=22.34 \mathrm{~kg}, \mathrm{~B}_{\mathrm{p}}=500 \mathrm{~N} / \mathrm{m} / \mathrm{s}, \mathrm{K}_{\mathrm{p}}=11624.85 \mathrm{~N} / \mathrm{m}$.

The objective was to design a state variable feedback plus integral controller to reject road disturbance input $\mathrm{r}$, maintain $\mathrm{x}_{\mathrm{b}}$ at a desired reference value, and keep $\dot{x}_{b}$ at zero after a transient period of 1 second $^{13}$. 
After extensive Matlab-Simulink computer simulations and some laboratory experimentation, the pole placement design method was selected. The following desired closed loop poles in the s-plane were chosen:

$$
\begin{aligned}
& s_{1,2}=-10.48 \pm j 16.34 \\
& s_{3,4}=-9.7984 \pm j 6.722
\end{aligned}
$$

Using the poles for pole placement design resulted in a control law,

$$
b i=k_{1}\left(x_{b d e s}-x_{b}\right)+k_{2} \int\left(x_{b d e s}-x_{b}\right) d t+k_{3}\left(\dot{x}_{b d e s}-\dot{x}_{b}\right)
$$

where,

$$
\begin{aligned}
& k_{1}=5 / 16 \\
& k_{2}=18.75 \\
& k_{3}=6.25 \times 10^{-4} \\
& \mathrm{x}_{\text {bdes }}=\text { desired reference value of } \mathrm{x}_{\mathrm{b}} . \\
& \dot{\mathrm{x}}_{\text {bdes }}=\text { desired reference value of } \dot{\mathrm{x}}_{\mathrm{b}} .
\end{aligned}
$$

A sampling interval $\mathrm{T}_{\mathrm{s}}=0.01 \mathrm{sec}$ was selected to convert the continuous time controller to a discrete time controller for implementation on the Motorola $68 \mathrm{HC} 16$ microcontroller ${ }^{14-15}$. The corresponding gains for the discrete time controller became:

$$
\begin{aligned}
& k_{1 d}=5 / 16 \\
& k_{2 d}=3 / 16 \\
& k_{3 d}=1 / 16
\end{aligned}
$$

with corresponding closed loop system poles in the z-plane at:

$$
\begin{aligned}
& z_{1,2}=0.8885 \pm j 0.1465 \\
& z_{3,4}=0.9046 \pm j 0.0609
\end{aligned}
$$

Let $\mathrm{k}$ be the sampling instant and let $\mathrm{e}(\mathrm{k})=\mathrm{x}_{\mathrm{bdes}}(\mathrm{k})-\mathrm{x}_{\mathrm{b}}(\mathrm{k})$, then the discrete time controller equation can be written as:

$$
b_{i}(k)=b_{i}(k-1)+\frac{1}{16} e(k-2)-\frac{7}{16} e(k-1)+\frac{9}{16} e(k)
$$

An assembly language program was written to implement equation (14). First desired reference values of $\mathrm{x}_{\text {bdes }}$ and $\dot{\mathrm{x}}_{\text {bdes }}=0$ were selected and stored on the microprocessor. An initial command signal from the microcontroller to the automatic binary regulator set $\mathrm{x}_{\mathrm{b}}=\mathrm{x}_{\text {bdes }}$ and $\dot{\mathrm{x}}_{\text {bdes }}=0$. After that, the road disturbance input $r$ was applied and the signals $\mathrm{x}_{\mathrm{b}}$ and $\dot{\mathrm{x}}_{\mathrm{b}}$ from the position and velocity sensors were converted to digital form by 10 bit analog to digital converters. The microcontroller solved equation (14) to reject the road disturbance input $r$.

In order to prevent oscillation around the desired reference value of $\mathrm{x}_{\mathrm{bdes}}$, a dead band error of $0.0018 \mathrm{~m}$ was included in the control program. If the error between $\mathrm{x}_{\mathrm{bdes}}$ and $\mathrm{x}_{\mathrm{b}}$ was within the deadband, no control action was taken by the microcontroller. The assembly language program which is five pages long can be obtained from the first author. 
One preliminary experimental result is now presented. The bottom of the suspension system was raised $0.01143 \mathrm{~m}$ and dropped. This represented a negative road disturbance step input $r$. Figure 11 shows the response of the system with no control.

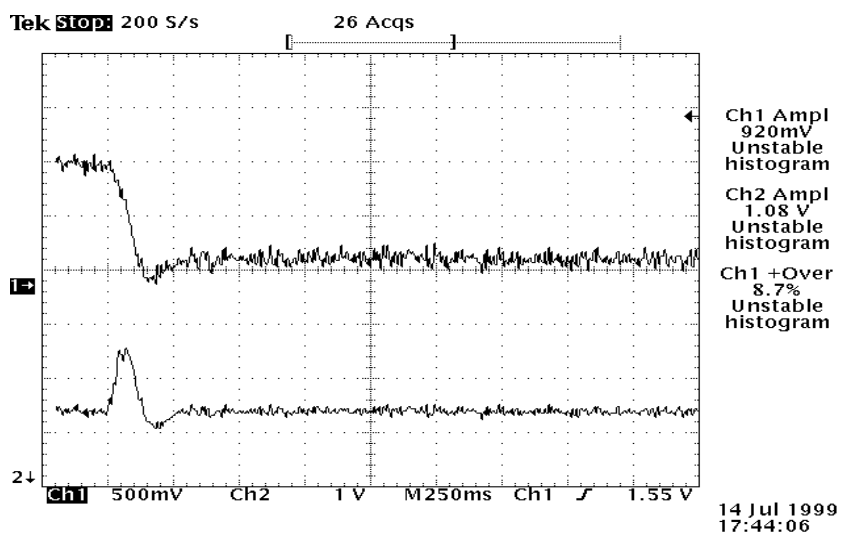

Figure 11. Response of System to a Negative Step Input With No Controller in the Loop.

In Figure 11, the upper curve is displacement $\mathrm{x}_{\mathrm{b}}$ and the lower curve is velocity $\dot{\mathrm{x}}_{\mathrm{b}}$.

Figure 12 shows the response of the system with the microcontroller in the loop.

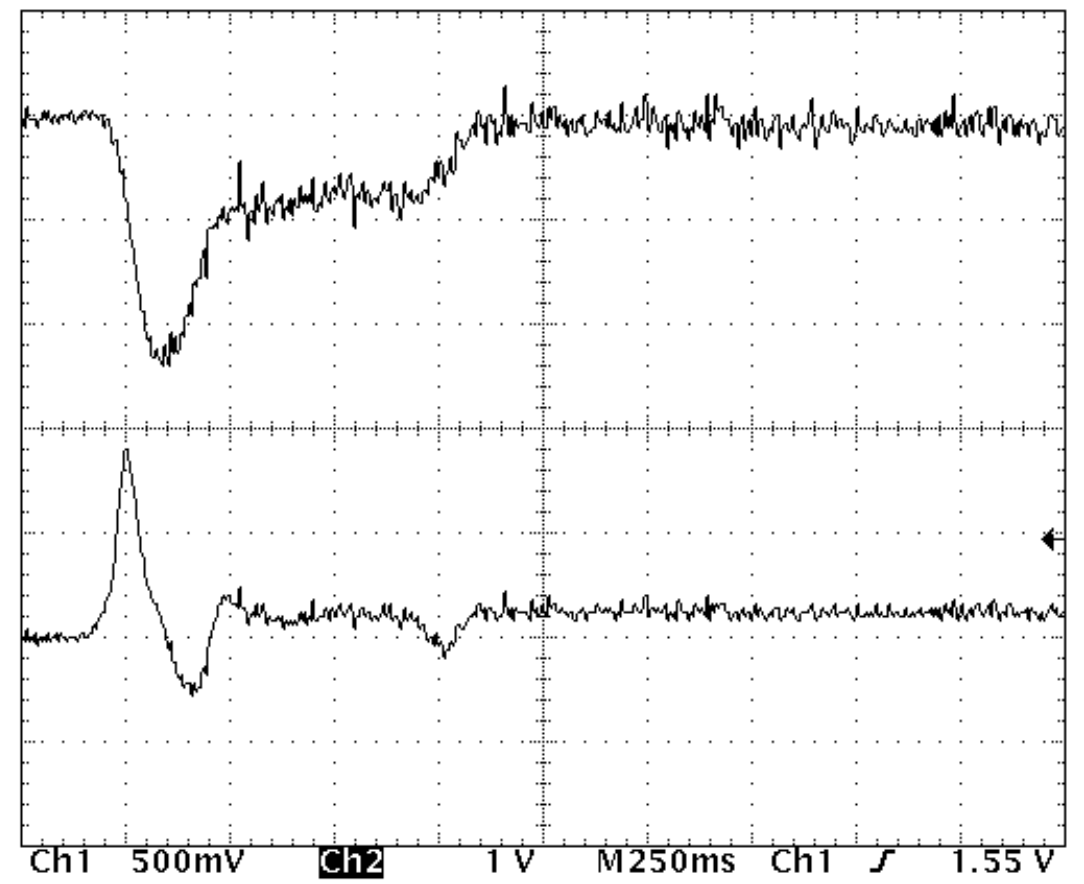

Figure 12. Response of System to a Negative Step Input with Microcontroller in the Loop.

In Figure 12, the upper curve is displacement $\mathrm{x}_{\mathrm{b}}$ and the lower curve is velocity $\dot{\mathrm{x}}_{\mathrm{b}}$. The response curves in Figure 12 showed that the system was able to recover from the road disturbance input in approximately $750 \mathrm{~ms}$. The speed of response 
can be increased by tuning the controller gains. Additional experimental work is in progress to tune the controller gains and apply sinusoidal and square wave disturbance inputs to the system. Future student projects will include design and implementation of gain scheduling, non-linear and robust control algorithms ${ }^{16-18}$.

\section{Conclusions}

This paper has described a prototype pneumatic active suspension system, which was designed and built over a number of years as a sequence of student design projects. During the design phase, the students gained experience in selection and integration of system components using knowledge of electro-mechanics, electronics, pneumatics, sensors, actuators and microcontrollers. The prototype active suspension system is a useful tool for analytical modeling and experimental modeling from input-output data. After a student has developed a model and validated it experimentally, different control algorithms can be designed and implemented on the Motorola $68 \mathrm{HC} 16$ microcontroller. In addition to control experimentation, students can use the system to learn assembly language programming and hardware interfacing using the eight analog to digital converters and the port of the Motorola 68HC16 microcontroller.

The prototype pneumatic active suspension system is a fairly complex physical plant which makes it possible for students to perform industrial level control experimentation.

\section{Acknowledgement}

The authors would like to thank Kress Corporation for providing free engineering services, Mr. Edgar Anglin for the use of his compressor, Mr. David Miller, Mr. Chris Mattus and Mr. Steve Gutschlag for their technical assistance.

The authors are very grateful to the Department of Electrical and Computer Engineering of Bradley University for providing the funds for the development of the active suspension system.

The authors would also like to thank Ms. Kathy Polen for preparing the manuscript.

Bibliography

1. D. Cho, and J.K. Hedrick, "Pneumatic Actuators for Vehicle Active Suspension Applications," ASME Journal of Dynamic Systems, Measurement, and Control, Vol. 107, pp. 67-72, March, 1985.

2. C. Yue, T. Butsuen, and J.K. Hedrick, "Alternative Control Laws for Automotive Active Suspensions," ASME Journal of Dynamic Systems, Measurement, and Control, Vol. 111, pp. 286-291, June 1989.

3. Ka C. Cheok, Nan-Khang Loh, H. Dean Mcgee, and Thomas F. Petit, " Optimal ModelFollowing Suspension with Microcomputerized Damping." IEEE Transactions on Industrial Electronics, Vol. IE-32 No. 4, pp. 364-371, November 1985. 
4. Ka C. Cheok, and Myoungho Sunwoo, "An Application of Explicit Self-Tuning Controller to Vehicle Active Suspension Systems," Proceedings of the $29^{\text {th }}$ Conference on Decision and Control, pp. 2251-2257, December 1990.

5. D. Hrovat, "Optimal Active Suspension Structures for Quarter-car Vehicle Models," Automatica, Vol. 26, No. 5, pp. 845-860, 1990.

6. Toshio Aburaya, Masaki Kawanishi, Hiroshi Kondo, and Toshiaki Hamada, "Development of an Electronic Control System for Active Suspension," Proceedings of the $29^{\text {th }}$

Conference on Decision and Control, pp. 2220-2225, December 1990.

7. T. Tseng, and D. Hrovat, "Some Characteristics of Optimal Vehicle Suspensions Based on Quarter-Car Models," Proceedings of the $29^{\text {th }}$ Conference on Decision and Control, pp. 2232-2237, December 1990.

8. Masaharu Satoh, Naoto Fukushima, Yousuke Akatsu, Itaru Fujimura, and Kensuke Fukuyama, "An Active Suspension Employing an Electrohydraulic Pressure Control System," Proceedings of the $29^{\text {th }}$ Conference on Decision and Control, pp. 2226-2231, December 1990.

9. A. Alleyne and J.K. Hedrick, "Nonlinear Control of a Quarter Car Active Suspension," Proceedings of the 1992 American Control Conference, pp. 21-25.

10. A. Alleyne, P.D. Meuhaus, and J.K. Hedrick, "Application of Nonlinear Control Theory to Electronically Controlled Suspensions," Vehicle System Dynamics, Vol. 22, pp. 309-320, 1993.

11. Kress Corporation, Brimfield, Illinois.

12. Matlab Version 5.2. Mathworks, Inc. 1999.

13. Gene Franklin, J. David Powell and Michael Workman, "Digital Control of Dynamic Systems," Addison Wesley, 1998.

14. CPU16 Reference Manual, Motorola Inc.

15. M68HC16Z1EVB Users Manual, Motorola Inc.

16. Jung-Shan Lin and Ioannis Kanellakopoulos, "Nonlinear Design of Active Suspensions," IEEE Control Systems Magazine, June 1997, pp. 45-59.

17. J.E. Bobrow and F. Jabbari, "Adaptive Pneumatic Force Actuation and Position Control," ASME Journal of Dynamic Systems, Measurement and Control, Vol. 113, pp. 267-272, June 1991.

18. M. Yamashita, K. Fujimori, C. Uhlik, R. Kawatani, and H. Kimura, " $\mathrm{H} \infty$ Control of an Automotive Active Suspension," Proceedings of the $29^{\text {th }}$ Conference on Decision and Control, pp. 2244-2250, 1990. 